\title{
Gender Differences In Job Attribute Prefe- rences And Job Choice Of University Students In China
}

Irene Hau Siu Chow, (Email: irene@baf.msmail.cuhk.edu.hk), Chinese University of Hong Kong Hang-yue Ngo, (Email: hyngo@baf.msmail.cuhk.edu.hk), Chinese University of Hong Kong

\begin{abstract}
This study investigates the gender differences in job attribute preferences and job choice among a group of university students in China. Due to the shortage of well-trained professionals and managers in China, both foreign and Chinese organizations compete for highly trained candidates. Correlation and regression analysis on data from 1,231 university students in China were used to test three hypotheses. Similarities between how men and women view the importance of advancement, compensation, and learning and overseas opportunities, in employment by foreign and national enterprises, were observed. But, on issues of job security, firm size, and nationality of supervisor, gender differences were present. Implications on employee recruitment for Chinese and foreign enterprises are discussed and suggestions for future research are provided.
\end{abstract}

\section{Introduction}

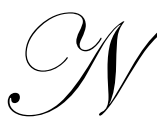

umerous studies have been conducted over the past several decades to explore gender differences with respect to occupational decisions. Researchers have investigated the factors affecting job choice decisions among male and female college students. These studies focused on work values of an ideal job, the role of social-psychological factors such as individual differences, career orientation, and sex-role socialization. These works have enhanced our understanding of the gender differences in job choice and vocational behavior, particularly in the context of Western countries. However, few studies have been done in socialist countries such as People's Republic of China that has undergone dramatic social and economic transformations during the last two decades. Previous studies have demonstrated that Chinese workers hold some specific work values, largely due to the unique social-cultural tradition and the socialist system in PRC. Recent university graduates have grown up in a more affluent and market-oriented economic environment, and consequently their work values are likely to be different from the earlier generations. A recent study has shown that the young generation tends to adopt more competitive and proactive attitudes toward work. They are likely to take risks, to create opportunities to learn, and to seek feedback about their performance (Weldon \& Vanhonacker 1999). It is thus important to examine their work values and job choice behavior.

\section{Purposes and Significance of the Study}

Our focus in this paper is to investigate the gender differences in job preferences and choice in the context of China. Specifically, we examine whether gender acts upon the relationship between job choice factors (such as compensation scheme, advancement possibilities, opportunities to learn, and job security) and perceived attraction of firms (i.e., FIEs versus SOEs). This study is of importance for the following reasons. First of all, it fills a research void in the existing literature, given that few studies on job choice and firm attractiveness have been done so far in China. It is interesting to know the work values and job preferences of university students under economic transition. Second, it aims to advance our knowledge by testing several hypotheses regarding the role of gender in

Readers with comments or questions are encouraged to contact the authors via email. affecting individual's job choice in the context of China. Third, results from the present study will provide some 
implications for firms in recruiting staff and for the Chinese government to achieve gender equality in employment. The present study offers practical importance for business in how to attract, retain and motivate young job candidates entering the managerial and professional ranks.

\section{Review of the Relevant Literature}

There is a substantial body of research which points to the gender differences in vocational interests or job attribute preferences and in the jobs graduates choose to do (Bokemeier \& Lacy 1986, McKeen \& Bu 1998, Tolbert \& Moen 1998). Such differences are often attributable to two factors: (1) sex-role socialization which creates a clear distinction between sex roles, and (2) prejudice and discrimination which affects status of women in the economy. These disadvantages faced by women, together with other gender-based constraints such as familial responsibilities, are likely to influence the opportunity structure and job choice decisions of female graduates.

\section{Gender Differences in Vocational Interests and Occupational Choice}

Gender-roles have been widely investigated in relation to occupational decision making. Many gender differences in job choice decisions are due to the influence of normative social expectations. Children are socialized to behave in a gender-appropriate manner. Consequently, they develop their perceptions of appropriate occupational choices to those associated with their own sex (Gottfredson 1981, Eagly 1987).

The sex-role socialization theory explains the process by which individuals learn the behavior that a culture defines as appropriate for their sex (Eagly 1987). It further provides explanation about sex differences in occupational orientation, job related skills, and career choice (Marini \& Brinton 1984). A summary of major literature along that line is provided in Table 1. Discrimination and sex segregation of occupation can be evidenced by young women are opting for "female-typed" occupations, whereas young men tend to enter "male-typed" jobs (Bokemeier \& Lacy 1986, Jurgensen 1978, Tolbert \& Moen 1998, Tomkiewicz, Brenner \& Damanpour 1994). This is particularly true in the traditional Chinese culture that has been adhering to rigidly defined gender roles and behaviors (Antonious \& Whitman 1995, Lin \& Xie 1988). Chinese women used to play a secondary and subordinate role in the public domain, and they occupied an inferior status in the society. Since 1949, however, China has espoused a national policy of gender equality. More educational and employment opportunities have been offered to women. As a result, the sexual division of labor became less marked and the status of women improved over time. Despite these, some gender differences in employment continue to exist (Lin \& Xie 1988, Ngo 2000).

\section{Gender, Work Values, and Job Choice Decisions}

A substantial amount of research has been done to identify sources of gender differences in work values (Chusmir \& Parker 1991, Nieva \& Gutek 1981). Women generally place greater importance on working conditions (e.g., flexible working schedule, less demanding job nature, child-care facilities, and family-oriented sick leave policy) that affect their involvement and commitment in the workplace. In addition, they hold preferences for certain job features which allow them to fulfill dual roles as employees and homemakers. Table 2 summarizes the relevant literature.

In a study comparing work goals by gender in three types of firms (i.e., American, Japanese and Taiwanese), it was found that Chinese men in American and Taiwanese firms value advancement opportunities more highly than Chinese women. On the other hand, women valued task challenge and contributing to company success lower than men only in Taiwanese firms. Personal and family time are more highly valued by women in Japanese firms (Yeh \& Granrose 1993). The apparent gender differences in work goals could be explained by either sex role socialization or perceived inequalities in conditions of employment among firms. Other research indicates that women and men in the same jobs are similar in career involvement and work values when educational level and other work-related factors were controlled (Brief, Rose \& Aldag 1977).

Table 1 Gender Differences in Vocational Interests and Occupational Choices 


\section{$\underline{\text { Author(s) }}$}

Gottfredson 1981;

Whyte \& Parish 1984

Eagly 1987;

Davey \& Stoppard 1993

Bokemeier \& Lacy 1986;

London \& Creller 1991;

Marini \& Brinton 1984

Moss \& Frieze 1993

Konrad, Ritchie, Lieb \& Corrigall 2000

Jurgensen 1978;

Swanson \& Takar 1991;

Tolbert \& Moen 1998

Antonious \& Whitman 1995; Lin

\& Xie 1988

Chan, Liu \& Zhang 1998; Leung \& Westwood 1998

Ngo 2000

Brooks, Cornelius, Greenfield \&

Joseph 1995;

Browne 1997;

Judge \& Bretz 1992;

Mason \& Mudrack 1996;

Tomkiewicz, Brenner \& Daman-

pour 1994;

\section{Key Dimensions, Sample, and Findings}

Children are socialized to behave in a gender-appropriate manner and develop their perceptions of sex appropriate occupational choice.

Individuals learn social behaviors appropriate for their sex.

(grade 10-12 Canadian high school)

Based on national longitudinal survey of young Americans and 1970 Census

data, men and women are different in occupation orientation, job-related

skills, and career choice.

Males are socialized to be assertive, authoritative, competent in occupational skills; females are socialized to be nurturing, deferent, competent in domestic skills (US MBA students).

Meta-analysis from 242 US data sets revealed significant gender-typed differences in job preferences.

Males preferred leadership, earnings, freedom, responsibility, promotion opportunities, power, and prestige.

Due to discrimination and socialization, women are excluded from some

non-traditional occupations (Career related barriers perceived by US college students).

Rigidly defined gender roles and behaviors in Chinese culture, women used to play a secondary and subordinate role and inferior status in society (middle managers from government, business, SOEs and collective enterprises in PRC).

Prejudice and discrimination against women in the workplace affect their job choice (Chinese employees in China's JVs ).

Institutional factors in China affect men and women's employment options and hence the pattern of occupational sex segregation.

Gender differences were also found in work values, job choice, and career orientation in different national samples, e.g., US college students, graduate business majors in US, US and Canada undergraduate students, American and Australia business students.
Basis for

H3

H3

$\mathrm{H} 3$

$\mathrm{H} 3$

$\mathrm{H} 3$

H1

H1

$\mathrm{H} 1$

H1

H1

As pointed out by Geib and Lueptow (1996), gender differences in work values may constitute an important aspect of occupational choice. Such differences may affect the differential career choices of men and women and facilitate their entry into male-dominated and female-dominated occupations in their early career stage. This argument is likely to hold in the context of China, as its labor market has been liberalized since the 1980s.

In a study of job choice of young professionals in China, the top three attributes are: personal interest, opportunity for practicing the knowledge and training that one had learned, and starting salary which is consistent with one's expectation (Fung, et al. 1996). In China, pay is frequently ranked at the top of the list in several studies (Ding 1999, Fisher \& Yuan 1998, Westwood \& Leung 1996). This reflects a primary instrumental orientation of the Chinese in the reform era. Both male and female employees consistently ranked high salary and good working conditions as the top two priorities on the list. Fung et al.'s study (1996) revealed that the first two reasons for leaving a job were dissatisfied with current position or career opportunity and pay/compensation. Chinese young professionals tend to take a more instrumental view of their work, and therefore they favor extrinsic rewards over intrinsic rewards. Job security was considered to be less important because jobs in state-owned enterprises are quite secured, whereas job opportunity in foreign managed firms seems prosperous. Additionally, Fisher and Yuan (1998) found very few differences between male and female employees with respect to several job preferences, such as wages, working conditions, interesting work, promotion and growth opportunities. However, an important gender difference lies in the preference for job security.

Table 2 Gender, Work Values and Job Choice Decisions 
Chusmir \& Parker 1991;

Nieva \& Gutek 1981

Betz \& O'Connell 1989;

Centers \& Bugenthal 1966

Yeh \& Granrose 1993

Bu \& McKeen 2001

Beief, Rose \& Aldag 1977

Fung et al. 1996

Ding 1999;

Goodall \& Burgers 1998;

Fisher \& Yuan 1998;

Westwood \& Leung 1996;

Fisher \& Yuan 1998

Weldom \& Vanhonacker 1999
Women prefer flexible working schedule, less demanding job, family-

friendly policy that allows them to fulfill dual roles as employees and homemakers.

Women rated family responsibilities, interpersonal relationships, personal fulfillment, and job security more important than men.

Men placed more emphasis on intrinsic factors, such as sense of accom-

plishment and opportunity to use talent, while women focused more on social relations at work (Pharmacy students in US).

In American \& Taiwanese firms, men value advancement opportunities more highly than women.

Women in Taiwanese firms rated task challenge and contributing to company success less important than men.

As compared with men, Chinese women gave higher priority to the work goals of balanced life and simplicity/routine. Both sexes were concerned about materialistic and intrinsic rewards.

No gender difference was found in career involvement and work values when educational level and other work-related factors were controlled.

Job choice of young professionals in China (employees in FIEs and university students in China), the top 3 attributes are:

(1) personal interest, (2) opportunity for practicing the knowledge and training that one had learned, and (3) starting salary.

High salary and good working conditions ranked top two priorities among Chinese youth.

Dissatisfied with career opportunity and pay are two reasons for shifting jobs.

Instrumental view of work, favor extrinsic rewards over intrinsic rewards. Little differences in job preferences between male and female employees such as wages, working conditions, interesting work, promotion and growth opportunities for a group of Chinese employees working for international hotel chain in Shanghai.

Significant gender difference in preference for job security.

The young generation in China tends to adopt more competitive and proactive attitudes toward work, willing to take risk, to create opportunities to learn, and to seek feedback about performance.

\section{Institutional Environment in China}

Environmental factors to a large extent provide the context and affect the development of an individual's work values. The unique institutional environment in China certainly would have a significant impact on one's occupational decision as it defines accepted options available to job applicants. Examples include government policies regulating the employment of college graduates, the differences in HR practices between SOEs and FIEs, social policies, and gender gaps in employment (Leung \& Westwood 1988, Ngo 2000). Such information about the institutional setting is important because it helps us to understand the constraints and opportunities faced by the male and female graduates and how these subsequently shape their job aspirations and job searching behavior.

The economic reform in China not only transforms its centrally-planned system to a more market-oriented one, it also creates more channels of employment alternatives and changes the work values and aspirations of young college graduates (Wang 1998). Before the economic reform in 1978, virtually all university graduates were assigned to a job in a SOE regardless of the individual's interests or qualifications. As part of the employment reform, university graduates are allowed to find their own jobs in the job market. More and more employment opportunities have been available in FIEs.

In a survey conducted by Shanghai City's Bureau of Higher Education in 1991, college graduates singled out FIEs as their favorite choice for employment. In 1996, a survey conducted by Beijing University revealed that $73 \%$ of the 206 college graduates considered "income" as the most important factor in selecting jobs (The Party Committee of Beijing University 1997). Ding (1999) also found that income and prospects were considered to be most important in career and job choice among the young Chinese. 
In socialist countries, SOEs are expected to fulfill a lot of the social responsibilities such as offering jobs and taking care of the social welfare and benefits of the workers. The employment system is characterized by low wage levels with comprehensive benefits and high job security. The over abundance of workers in the SOEs leads to high levels of idleness, absenteeism, low morale, and disrespect for management (Antonious \& Whitman 1995). One of the important motives among workers for joining joint ventures or FIEs is to avoid the negative aspects associated with employment in SOEs. They expect to be given greater levels of responsibility and be able to exercise more initiative. In general, FIEs are viewed as meritocracies, with rewards based on performance and implemented with fairness and equity. The workers in FIEs also expected more rapid promotion than if employed in a SOE (Westwood \& Leung 1996). The positive and negative factors associated with employment in SOEs and FIEs are summarized in Table 3.

\section{Table 3 Positive and Negative Factors Associated with SOEs and FIEs}

\begin{tabular}{|c|c|c|}
\hline Attraction Factors & $\underline{\text { SOES }}$ & $\underline{\text { FIEs }}$ \\
\hline Positive Factors & $\begin{array}{ll}\text { - } & \text { Comprehensive benefits } \\
\text { - } & \text { Less stressful work environment } \\
\text { - } & \text { Lebs security } \\
\text { - } & \text { Egalitarian reward }\end{array}$ & $\begin{array}{ll}\text { - } & \text { More opportunities for advancement } \\
\text { - } & \text { Greater starting pay } \\
\text { - } & \text { ages } \\
\text { - } & \text { More competent co-workers \& supervisors } \\
\text { - } & \text { one's ability } \\
\text { - } & \text { Metter training and development programs } \\
\text { - } & \text { Rewarding hard work } \\
\text { - } & \text { More flexible employment system } \\
\text { - } & \text { Less bureaucratic \& more efficient }\end{array}$ \\
\hline Negative Factors & $\begin{array}{l}\text { - } \quad \text { How wages } \\
\text { morale, disrespect for management } \\
\text { - } \quad \text { Overstaffing, pressure to downsize } \\
\text { - } \quad \text { Low task commitment, weak ethic } \\
\text { - } \quad \text { Reward not linked to performance } \\
\text { Rigid and inflexible systems stifle crea- } \\
\text { tivity and initiatives } \\
\text { Passive, unmotivating \& responsibility- } \\
\text { avoiding cultures }\end{array}$ & $\begin{array}{ll}\text { - } & \text { No long-term job security } \\
\text { - } & \text { Long working hours } \\
\text { - } & \text { Less comprehensive benefits coverage } \\
\text { - } & \text { Stressful and competitive working envi- } \\
& \text { ronment }\end{array}$ \\
\hline
\end{tabular}

\section{Hypotheses}

It is argued that male and female job applicants have differential preferences for SOEs and FIEs, given these firms have different characteristics. In particular, women may have more opportunities to learn and to have better career development in FIEs which have fairer human resource management practices. Moreover, women are likely to suffer more gender-based discrimination in SOEs (Ngo 2000). For men, their gender becomes an advantage when they work in SOEs, and thus they may have a stronger preference for working for SOEs as compared with women. Based on the above discussion, the following hypothesis is proposed:

Hypothesis 1: Perceived overall attraction of FIEs is higher for women than for men, while perceived overall attraction of SOEs is higher for men than for women.

The person-organization fit approach suggests that an individual will choose to work in an organization that fits his or her personal orientations and job preferences. It follows that workers may seek employment in organizations 
with certain characteristics, given their own job attribute preferences. Thus, the following hypothesis is formulated:

Hypothesis 2: Individual job choice factors are related to one's perceived overall attraction of firms. More specifically, an individual who places more value on compensation, career advancement, and opportunities to learn will prefer to work in FIEs. An individual who places more value on job security will prefer to work in SOEs.

Since men and women are theorized to differ with respect to their job attribute preferences and attractiveness to SOEs and FIEs, we propose the following hypothesis:

Hypothesis 3: The relationship between job choice factors and perceived overall attraction of firms differs with gender.

This is because, as a result of sex-role socialization, men and women are likely to have different evaluations of job choice factors. Men in general place higher value on compensation package and advancement possibilities, while women emphasize job security and opportunities to learn. These differential evaluations of job choice factors, in turn, may affect how men and women perceive the attractiveness of SOEs and FIEs.

\section{Methodology}

Data Collection

Data were collected by means of a self-administered questionnaire completed by college students in seven major universities in China. The questionnaire was printed in Chinese characters. Respondents were asked to indicate their perceptions of working conditions and attractiveness to a job with a typical foreign-invested and stateowned enterprise.

\section{Sample characteristics}

Subjects were 1231 students (769 males, and 460 females, two of the respondents did not identify their gender) at the major universities located in Shanghai and Beijing. They were primarily single (98\%), male (63\%), with an average age of 21.1 years. A majority of them were business majors (72\%), and there were also a substantial number of engineering (14\%) and science majors (7\%). Most of them reported graduating within one year $(62 \%)$ having no working experience $(61 \%)$.

\section{Measures}

The variables used in the statistical analysis were operationalized as follows:

Attractiveness to foreign-invested firms. This was measured using three items on a five-point Likert scale. These items were "A job in a foreign-invested enterprises would be very attractive to me", "I am willing to work for a foreign-invested enterprises" and "Foreign-invested enterprise satisfies my expectation on the job." They were then added together to create a scale, which has an alpha coefficient of 0.86 in the present study.

Attractiveness to state-owned enterprises. This was measured by a scale consisting of three items. The wordings of these items are the same as the above scale except "foreign-invested enterprises" was replaced by "state-owned enterprises". The alpha coefficient for this scale in the present study is 0.89 .

Relative Attractiveness. This was measured by subtracting the score of attractiveness to foreign-invested firms from that of attractiveness to state-owned enterprises. A positive value implies that the respondent has a preference for FIEs over SOEs, while a negative value implies the reverse.

Importance of job choice factors. Respondents were asked to evaluate the importance of eight different job choice 
factors using a five point Likert scale ( $1=$ not important at all, $5=$ very important). These job choice factors included compensation package, advancement possibilities, opportunities to learn on the job, opportunities for overseas travel, job security, firm size, nationality of firms, and nationality of supervisors.

In order to measure the relative impact of various job attribute factors on the attraction of SOEs and FIEs, separate regression analyses were employed to test the hypotheses. Perceived attraction of firms (i.e., FIEs, SOEs and their relative attractiveness) are the dependent variables. The predictors are various job choice factors which include (1) compensation package, (2) advancement possibilities, (3) opportunities to learn, (4) opportunities for overseas travel, (5) nationality of company, (6) nationality of supervisor, (7) job security, and (8) size of the company. The functional form of our analysis can be stated as follows:

Attractiveness to firms $=\beta_{0}+\beta_{1}$ (compensation package) $+\beta_{2}$ (advancement possibilities $)+\ldots . .+\beta_{8}$ (size of the company) $+\mathrm{e}$

\section{Results}

Respondents were asked to indicate the importance of each of the job attributes when he or she makes a decision to accept a job offer. Mean scores and rank orders for males and females are presented in Table 4. Results showed that male and female students differed significantly (at 0.05 level) on two job characteristics: nationality of the company and job security. Male students considered nationality of the enterprise more important than females, whereas female students considered job security more important than males in making a job decision. There were no gender differences in the degree of importance for other job choice factors. Significant differences in attraction to FIEs and SOEs between male and female students were also noted, with males indicating more attraction to SOEs, and females more attraction to FIEs. Thus, $\mathrm{H} 1$ was supported. As women generally have better career development opportunities in FIEs, they prefer to work in FIEs as opposed to SOEs. Additional analysis revealed no gender differences in the top three importance factors assigned and preference for SOEs and FIEs.

Table 4 Mean Importance Ratings and Rank Order of Job Attributes by Gender

$\begin{array}{lllllc}\text { Job Attributes } & \begin{array}{l}\text { Male } \\ \text { Mean }\end{array} & \text { Rank } & \begin{array}{l}\text { Female } \\ \text { Mean }\end{array} & \text { Rank } & \begin{array}{c}\text { Difference } \\ \text { t-test }\end{array} \\ \text { Advancement possibilities } & & & & & \\ \text { Opportunities to learn on the job } & 4.59 & 1 & 4.55 & 1 & 1.027 \\ \text { Compensation package } & 4.22 & 2 & 4.29 & 2 & -1.495 \\ \text { Opportunities for overseas travel } & 4.13 & 3 & 4.11 & 3 & .527 \\ \text { Job security } & 3.35 & 4 & 3.46 & 5 & -1.701 \\ \text { Size of the company } & 3.29 & 5 & 3.47 & 4 & -2.919^{* *} \\ \text { Nationality of company } & 3.20 & 6 & 3.30 & 6 & 2.183^{*} \\ \text { Nationality of supervisor } & 3.17 & 7 & 3.04 & 7 & 1.04 \\ & 2.81 & 8 & 2.75 & 8 & -3.04^{* *} \\ \text { Attraction to FIE } & & & & & 3.108^{* *} \\ \text { Attraction to SOE } & 3.67 & & 3.83 & & \end{array}$

Note: $1=$ not at all important, $5=$ very important

$* \mathrm{p}<.05$

$* * \mathrm{p}<.01$

The correlations among the study's variables are presented in Table 5. All pairs of variables have a correlation coefficient below 0.4 , except that of nationality of company and nationality of supervisor $(r=0.6 ; p<0.01)$. Most of the job attribute variables were negatively correlated to attraction to SOEs. Only job security has a significant and positive relationship with attraction to SOEs. Learning opportunity, firm size, and nationality of supervisor showed no significant correlation with attraction to SOEs. Therefore, $\mathrm{H} 2$ was supported. Contrary to our expecta- 
tion, attraction to FIEs was not significantly correlated with job security and nationality of supervisor.

Table 5 Correlation among Variables

\begin{tabular}{|c|c|c|c|c|c|c|c|c|c|c|c|}
\hline & $\underline{\text { Mean }}$ & S.D. & $\underline{\text { Sex }}$ & $\underline{1}$ & $\underline{2}$ & $\underline{\mathbf{3}}$ & $\underline{4}$ & $\underline{5}$ & $\underline{6}$ & $\underline{7}$ & $\underline{8}$ \\
\hline 1. Advancement opportunity & 4.58 & .68 & -.03 & & & & & & & & \\
\hline 2. Learning opportunity & 4.24 & .76 & .043 & $.37 * *$ & & & & & & & \\
\hline 4. Overseas opportunity & 333.39 & 1.05 & .05 & $.20 * *$ & $.19 * *$ & $.24 * *$ & & & & & \\
\hline 5. Compensation & 4.12 & .76 & -.02 & $.28 * *$ & $.07 * *$ & .05 & $.13 * *$ & & & & \\
\hline 6. Job Security & 3.36 & 1.01 & $.08 * *$ & $-.08 * *$ & $.07 *$ & .05 & $.09 * *$ & $.10^{* *}$ & & & \\
\hline 9. Attraction to FIE & 3.73 & .87 & $.09 * *$ & $.21 * *$ & $.15^{* *}$ & $.13^{* *}$ & $.24 * *$ & $.23 * *$ & .02 & $.02 * *$ & .02 \\
\hline $\begin{array}{l}\text { 10. Attraction to SOE } \\
\text { Note: } * \mathrm{p}<.05 \\
* * \mathrm{p}<.01\end{array}$ & 2.67 & .91 & $-.09 * *$ & $-.08 * *$ & .003 & $-.09 * *$ & $-.11 * *$ & $-.13 * *$ & $.09 * *$ & .01 & -.01 \\
\hline
\end{tabular}

Multiple regression analysis was then conducted to determine whether the predictors were related to attraction to FIEs and SOEs respectively. The results of the regression analysis are presented in Table 6 . The tolerance values of the independent variables suggest that collinearity is not a problem in our analysis ${ }^{1}$. The F-statistic for all the regression models are significant at 0.01 level. As shown in Table 6, the job choice factors differentially affected the attractiveness of FIEs and SOEs among the respondents, with the exception of learning opportunity. In particular, respondents who place more value on compensation, advancement opportunities, opportunities for overseas travel, and firm ownership tended to be more eager to work for FIEs. On the other hand, those who place more value on job security and less on compensation hold a preference for working for SOEs. College students who are attracted to FIEs considered learning opportunity and job security as relatively unimportant. Advancement and learning opportunity, firm size, and nationality of supervisor were not important for applicants seeking jobs with SOEs. Some gender differences are noteworthy. For those who are attracted to FIEs, firm size is an important consideration for males but not for females. Additionally, females who are concerned about the nationality of supervisor were less likely to seek jobs in FIEs. With regard to SOEs, it is found that firm nationality had a negative effect for males, while opportunities of overseas travel had a negative effect for females, but these effects did not show up for the opposite sex. In view of the above results, H3, which states that the relationship of job choice factors and attractiveness of firms differs by sex, has gained some empirical support. Turning to the relative attractiveness of FIEs versus SOEs, it is found that firm nationality, overseas opportunity, and compensation exerted positive effects for both genders. Respondents who value more of these job attributes have stronger preference to work in FIEs over SOEs. Moreover, male respondents who value more on advanced opportunity and less on job security prefer to work in FIEs rather than SOEs.

\section{Discussion and Conclusion}

It is noteworthy that there is a strikingly similarity in rank orders of the job attributes among male and female college students. There is lack of major gender differences in important job attributes, such as advancement, learning, overseas opportunities, and compensation package. Job security and nationality of company are the only two job attributes that differ significantly between male and female college students. Female students considered job security more important while male students viewed the nationality of the company as more important. This study thus provides some confirmation of gender differences in job attributes in the context of socialist China. However, the gender differences in preference for various job attributes is small even if statistically significant. The results of this study support a number of previous research findings and are consistent with several theories proposed in the literature (Betz \& O’Connell 1989, Fiorentine 1988, Mason \& Mudrack 1996, Moss \& Frieze 1993, Xie 1996).

Table 6 Summary of Regression Analysis

Attraction to FIE

$\underline{\text { Job Choice Factors }}$
Male
Attraction to SOE

$\underline{\text { Male }}$
Female

\author{
Relative Attractiveness \\ (FIE - SOE)
}




\begin{tabular}{|c|c|c|c|c|c|c|c|}
\hline \multirow{2}{*}{\multicolumn{2}{|c|}{ Advancement opportunity }} & Std. Beta & Std. Beta & Std. Beta & Std. Beta & Std. Beta & Std. Beta \\
\hline & & $.102 * *$ & $.117 *$ & -.036 & .018 & $0.084 *$ & 0.049 \\
\hline \multicolumn{2}{|c|}{ Learning opportunity } & .047 & .061 & .054 & -.024 & -0.005 & 0.069 \\
\hline \multicolumn{2}{|c|}{ Firm nationality } & $.091 *$ & $.146^{*}$ & $-.111 *$ & -.117 & $0.122 * *$ & $0.176^{* *}$ \\
\hline \multicolumn{2}{|c|}{ Overseas opportunity } & $.197 * * *$ & $.135 * *$ & -.071 & $-.132 *$ & $0.159 * *$ & $0.178 * *$ \\
\hline \multicolumn{2}{|l|}{ Compensation } & $.190 * * *$ & $.143 * *$ & $-.148 * * *$ & $-.107 *$ & $0.209 * *$ & $0.158 * *$ \\
\hline \multicolumn{2}{|l|}{ Job security } & -.014 & -.090 & $.121 * *$ & $.101 *$ & $-0.087^{*}$ & $-0.128 * *$ \\
\hline \multicolumn{2}{|l|}{ Firm size } & $.114^{* * *}$ & -.042 & .003 & .053 & 0.070 & -0.066 \\
\hline \multicolumn{2}{|c|}{ Nationality of supervisor } & -.065 & $-.135^{*}$ & .088 & -.026 & -0.088 & -0.071 \\
\hline \multicolumn{2}{|l|}{$\mathrm{F}$} & $16.457 * * *$ & $6.925 * *$ & $5.443 * *$ & $3.487 * *$ & $12.846^{* *}$ & $7.715 * *$ \\
\hline \multicolumn{2}{|l|}{$\mathrm{R}^{2}$} & 0.154 & 0.117 & 0.057 & 0.062 & 0.125 & 0.130 \\
\hline Note: & $\begin{array}{l}* \mathrm{p}<.05 \\
* * \mathrm{p}<.01 \\
* * * \mathrm{p}<.0\end{array}$ & & & & & & \\
\hline
\end{tabular}

Furthermore, the present study reveals that most of the job attributes, such as advancement opportunity, learning opportunity, overseas travel, compensation, and nationality of the company, are significantly correlated with attraction to FIEs and negatively correlated with attraction to SOEs. FIEs are perceived to be much more challenging and rewarding places to work than SOEs. This finding is consistent with earlier study by Westwood and Leung (1996) on the perceptions of SOEs and FIEs. Foreign-invested firms in China compete fiercely for the limited supply of well-trained and competent workers by offering generous compensation packages and better career prospects. As such, FIEs should pay attention to the types of job attributes these potential candidates are looking for and formulate the appropriate human resources strategy to attract and retain their Chinese staff.

Gender differences should be further explored in future research. Despite the fact that women preferred job security, they found jobs in FIEs more attractive. Women also showed a distinct negative response for the nationality of the supervisor in FIEs. It is also interesting to find that firm size has a positive effect on the attractiveness of FIEs for males, but not for females. Both male and female respondents look for jobs that provide advancement, overseas opportunity, good compensation and thus they prefer to be employed in FIEs. As for attraction to SOEs, an important concern for graduates is job security regardless of their sex. Lower compensation also makes SOEs less attractive for both male and female college students. However, we found that development and learning opportunity, firm size, and nationality of the supervisor did not exert any significant impacts on the attraction to SOEs. All in all, some gender differences have been noted in the present study which were not in evidence in previous studies. For example, men who are attracted to SOEs appeared to be less concerned with overseas experience, but more concerned with firm nationality. More studies are called for to understand these unique patterns in China.

Several limitations of the present study should be noted. The reliance on self-reported data and the use of a single questionnaire to collect the data raised concern about common method variance. The present study is restricted to college students with limited working experience. Young workers are more likely to hold idealistic work values when compared to older, more experienced workers. The preferences for job attributes may change with age and career stage. The restriction of range may reduce the study's explanation power. Follow-up studies from numerous organizations in different locations covering a large range of occupations and age groups will enhance the generalizability of the study.

\section{Practical Implications}

An employee's commitment to an organization is a function of fit between certain job attributes and what he or she hopes to get. The determination of vocationally relevant interest is an important component of both theories of occupational choice and career counseling. The present study presents new empirical results to fill the void in the existing literature. As for practical implications, applicant's perception of organizational attractiveness can influence his or her job pursuit intentions and acceptance of job offers (Smither, et al.1993). The job attribute preferences that have been identified can be used to evaluate the attractiveness of a particular job or type of organizations to job applicants. Such information can be used to match individuals to job and organization and improve the effectiveness of recruitment efforts. 
Companies that offer generous compensation, invest in training and development, provide better career opportunities are more likely to attract good job candidates. Gender differences in job attributes were not found to be profound in China. Chinese women are at least as interested in both extrinsic and intrinsic rewards as their male counterparts (Bu \& McKeen 2001). Despite women put greater importance on predictability and certainty on the job, they are more attracted to FIEs. In fact, job security in SOEs is no long guaranteed. Young women find working for FIEs offer better job opportunity and suffer less gender discrimination. In competing for managerial talents, organizations should not ignore the intelligent and competent female candidates and try to address their needs.

\section{Endnote}

1. Tolerance is a commonly used measure of collinearity. A low tolerance value (i.e., near 0) indicates problem of collinearity, while a high value (i.e., near 1) indicates that the independent variable is relatively independent of other variables. The tolerance values of the independent variables in this study are close to 1 .

\section{References}

1. Antonious, P. H. \& Whitman, K., Work related values of Chinese managers in the People's Republic of China. Journal of Asian Business, Vol.11, No.1, pp.77-97, 1995.

2. Betz, M. \& O'Connell, L., Work orientations of males and females: Exploring the gender socialization approach. Sociological Inquiry, Vol.59, pp.318-30, 1989.

3. Bokemeier, J. L. \& Lacy, W. B., Job values, rewards, and work conditions as factors in job satisfaction among men and women. The Sociological Quarterly, Vol.28, No.2, pp.189-204, 1986.

4. Brief, A. P., Rose, G. L., \& Aldag, R. J.), Sex differences in preferences for job attributes revisited. Journal of Applied Psychology, Vol.62, pp.645-646, 1977.

5. Brooks, L., Cornellius, A., Greenfield, E. \& Joseph, R.), The relation of career-related work or internship experiences to the career development of college seniors. Journal of Vocational Behavior, Vol.45, pp.332349, 1995.

6. Browne, B. A., Gender and preferences for job attributes: A cross-cultural comparison. Sex Roles, Vol.37, No. 1-2, pp.61-71, 1997.

7. Bu, N., \& McKeen, C. A., Work goals among male and female business students in Canada and China: the effects of culture and gender. International Journal of Human Resource Management, Vol. 12, No.2, pp.166-183, 2001.

8. Centers, R., \& Bugenthal, D. E., Intrinsic and extrinsic job motivation among different segments of the working population. Journal of Applied Psychology, Vol.50, No. 3, pp.193-197, 1966.

9. Chan, C., Liu, M., \& Zhang, Y., End of women's emancipation? In J. Cheng, (ed.), China in the PostDeng Era. Hong Kong: The Chinese University of Hong Kong Press, pp.589-616, 1998.

10. Chusmir, L. H. \& Parker, B.), Gender and situational differences in managers' values: A look at work and home live. Journal of Business Research, Vol. 23, 325-335.

11. Davey, F. H. \& Stoppard, J. M. (1993), Some factors affecting the occupational expectations of female adolescents. Journal of Vocational Behavior, Vol.43, pp.235-250, 1991.

12. Ding, X., Twenty years through the eyes of Chinese youth: A Survey. China Today, May, 1999.

13. Eagly, A. H., Sex differences in social behavior: A social-role interpretation. Hillsdale: NJ: Lawrence Erlbaum Associates, 1987.

14. Fiorentine, R. Increasing similarity in the values and life plans of male and female college students? Evidence and implications. Sex Roles, Vol.18, No. 3/4, pp.143-158, 1988.

15. Fisher, C. D. \& Yuan, A. X. Y., What motivates employees? A comparison of US and Chinese responses. The International Journal of Human Resource Management, Vol.9, No.3, pp.516-528, 1998.

16. Fung, C. K. W., Min, K. Z. \& Yong, W. W., Job choice and job mobility for Chinese young professionals. Hong Kong Manager, Nov-Dec., pp.20-25, 1996.

17. Geib, A. E. \& Lueptow, L. B., Sex, gender stereotypes, and work. New Brunswick: Rutgers University Press, pp.243-246, 1996.

18. Goodall, K. \& Burgers, W., Frequent fliers. The China Business review, May-June, pp.50-52, 1998.

19. Gottfredson, L. S., Circumscription and compromise: A developmental theory of occupational aspirations. 
Journal of Counseling Psychology, Vol. 28, pp.545-579, 1981.

20. Jurgensen, E. C., Job preference (What makes a job good or bad?) Journal of Applied Psychology, Vol.63, pp.267-276, 1978.

21. Judge, T. A. \& Bretz, Jr. R. D., Effects of work values on job choice decision. Journal of Applied Psychology, Vol.77, No.3, pp.261-271, 1992.

22. Konrad, A. M., Ritchie, Jr. J. E., Lieb, P. \& Corrigall, E., Sex differences and similarities in job attribute preferences: A meta-analysis. Psychological Bulletin, Vol.126, No.4, pp.593-641, 2000.

23. Leung, S. M. \& Westwood, R. I., Between dogma and reality: Women and employment in China. International Employment Relations Review, Vol.4, No.1, pp.57-73, 1998.

24. Lin, N. \& Xie, W., Occupational prestige in urban China. American Journal of Sociology, Vol.93, pp.793$832,1988$.

25. London, M. \& Greller, M. M., Demographic trends and vocational behavior: A twenty year retrospective and agenda for the 1990s. Journal of Vocational Behavior, Vol.38, pp.125-164, 1991.

26. Marini, M. M. \& Brinton, M. C., Sex typing occupational socialization. In Sex Segregation in the workplace: Trends, explanations, remedies, Washington, D.C.: National Academy Press, pp.192-232, 1984.

27. Mason, W. S. \& Mudrack, P. E., Gender and ethical orientation: A test of gender and occupational socialization theories. Journal of Business Ethics, Vol. 15, pp.599-604, 1996.

28. McKeen, C. A. \& Bu, N., Career and life expectations of Chinese business students: the effects of gender. Women in Management Review, Vol.13, No.5, pp.171-183, 1998.

29. Moss, M. K. \& Frieze, I. H., Job preferences in the anticipatory socialization phase: A comparison of two matching models. Journal of Vocational Behavior, Vol. 42, pp.282-297, 1993.

30. Ngo. H. Y., Trends in occupational sex segregation in urban China. Working paper, Department of Management, The Chinese University of Hong Kong, 2000.

31. Nieva, V. E. \& Gutek, B. A., Women and work: A psychological perspective. New York: Praeger, 1981.

32. Smither, J. W., Reilly, R. R., Millsap, R. E., Pearlman, K. \& Stoffey, R. W., Applicant reaction to selection procedures. Personnel Psychology, Vol.46, 49-76, 1993.

33. Swanson, J. L. \& Takar, D. M., College students' perceptions of barriers to career development. Journal of Vocational Behavior, Vol.38, pp.92-106, 1991.

34. The Party Committee of Beijing University, A survey of the Graduates of Beijing University. Qingnian Yanjiu (Youth Study). Beijing, No. 3, p.15, 1997.

35. Tolbert, P. A. \& Moen, P., Men's and women's definition of "good" jobs: Similarities and differences by age and across time. Work and Occupations, Vol.25, No.2, pp.168-194, 1998.

36. Tomkiewicz, J., Brenner, O. C., \& Damanpour, F., Gender differences in job orientation: Have they changed? Journal of Global Business, Vol.5, pp.65-76, 1994.

37. Wang, J.), The evolution of the PRC's policies governing college graduates' employment. Issues and Studies, Vol.34, No. 3, pp.25-50, 1998.

38. Weldon, E. \& Vanhonacker, W., Operating a foreign-invested enterprise in China: Challenges for managers and management researchers. Journal of World Business, Vol.34, No.1, pp.94-107, 1999.

39. Westwood, R. I. \& Leung, S.M., Work under the reforms: The experience and meaning of work in a time of transition. In China Review 1996, Hong Kong: The Chinese University of Hong Kong Press, pp.367423, 1996.

40. Whyte, M. K. \& Parish, W.L., Urban life in contemporary China. Chicago: The University of Chicago Press, 1984.

41. Xie, J. L., Karasek's model in the People's Republic of China: Effects of job demands, control, and individual differences. Academy of Management Journal, Vol.39, No.6, pp.1594-1618, 1996.

42. Yeh, R. H. \& Granrose, C. S., Work goals of Taiwanese men and women managers in Taiwanese, Japanese and American owned firms. International Journal of Intercultural Relations, Vol.17, pp.107-123, 1993.

Notes 